\title{
Using Modified Similarity Multiple Criteria Decision Making technique to rank countries in terms of Human Development Index
}

\author{
Hossein Safari, Elham Ebrahimi \\ University of Tehran (Iran) \\ bsafari@ut.ac.ir,elhebrabimi@ut.ac.ir
}

Received: April 2013

Accepted: February 2014

\section{Abstract:}

Purpose: Human Development Index (HDI) reported annually by the United Nations Development Program (UNDP) is a popular measure of human well-being. The purpose of this study is to propose a Multiple Criteria Decision Making (MCDM) technique named Modified Similarity technique for ranking countries based on multi-criteria HDI.

Design/methodology/approach: In Human Development Reports (HDRs), the HDI for each country is first calculated from the average of the health, education and income dimension indices with equally allocated weight. Then the countries are ranked based on this index. Regarding the criticisms (that) the method of calculating the HDI has received, this study uses Modified Similarity Multi Criteria Decision Making method for ranking countries based on multi-criteria HDI, as an alternative method to the average method, which is being used in annually reported HDRs.

Findings: We used the four HD indices mentioned in the 2010 and 2011 HDRs to rank 187 countries which have been investigated in the 2011 HDR. The results of ranking countries by the Modified Similarity technique were somewhat different from the 2011 HDR ranking.

Originality/value: Some of the HDI criticisms are related to the method of calculating this index in the form of computing the average of the three health, education and income dimension indices with equally allocated weights. In an attempt to eliminate some of the 
weaknesses which are associated with the index, this study uses Similarity technique, as an alternative to the average method of ranking countries in terms of human development. In addition, due to some discrepancies associated with the Similarity technique introduced by Deng (2007), a Modified Similarity technique is discussed.

Keywords: multiple criteria decision making, modified similarity technique, human development index

\section{Introduction}

Human development can be determined as the process of bringing freedom and opportunities for people and sublimating their wellbeing. This concept was developed by Mahbub ul Haq, an economist who argued that human development is an approach which is concerned with advancing the richness of human life. He believed in failing the existing measures of human progress to account for the basic purpose of development, which is to improve people's lives (Yassin, Shaffril, Hassan, Othman, Samah, Samah et al, 2011).

In 1989 United Nations Development Program (UNDP) sponsored a project to develop an index for better understanding and measuring development in countries across the world. This project resulted in creating the Human Development Index (HDI). The primary aim of this index was to rank countries based on the composite scores of multiple components. The major advantage of this scale is that it incorporates the traditional economic component with two other components, including a biological measure of life expectancy and a cultural measure of education (Porter \& Purser, 2008).

Indeed, unlike the objectives of the first, the second and the third UN development decades (1960, 1970, 1980) which mostly focused on economic growth, the objective of promoting human wellbeing that entails dignity, freedom and equality for all people, was an approach advocated by the Human Development Report since its inception (UNDP, 2003).

After introducing the HDI, the UNDP published a report in 1990, in which the index was computed for each country as a measure of the nation's human development. Since then UNDP has continued publishing a series of annual Human Development Reports (HDRs).

The first HDR implied that human development is more than just income, wealth and accumulating capital and it defined human development as the process of enlarging people's choices. The most critical choices are to live long and healthy, to be educated and to have access to resources for a decent standard of living (UNDP, 1990).

Despite the comprehensiveness of the HDI in its simultaneous attention to the economic, social and biological components, it has always provoked criticisms from some scholars and policy 
makers. Some of these criticisms are related to the method of calculating the index in the form of computing the average of the three health, education and income dimension indices with equally allocated weight (see, e.g., Kelley, 1991; Srinivasan, 1994; Ravallion, 1997; Ravallion, 2012). Therefore, in an attempt to eliminate some of the weaknesses associated with the index, this study uses Modified Similarity Multi-Criteria Decision Making (MCDM) method, as an alternative to the average method of ranking countries in terms of human development.

In this regard the next section introduces the three dimensions and the four indicators which form the HDI, and then the methodology which is used to calculate the HDI in 2010 and 2011 HDRs, is presented. It is followed by enumerating some of the important criticisms with which the HDI has been faced during its 20-year history. In section 3, a brief explanation of the MCDM approach and the TOPSIS technique as one of the best MCDM techniques, are presented. In addition, some of the problems which may be caused by using this technique are expressed. After that, in order to reduce some of the faults with the HDI calculation, which are implied by a group of criticisms, we present the Similarity technique which is an efficient MCDM technique that overcomes the problems caused by the TOPSIS method. Due to some discrepancies associated with the technique introduced by Deng (2007), a Modified Similarity technique is discussed. Finally ranking of the countries reported in 2011 HDR, is presented through the Modified Similarity technique.

\section{The Human Development Index}

The HDI is a composite measure of country-level achievements in three basic dimensions of human development: a long and healthy life, access to education and a decent standard of living (UNDP, 2010). The HDI scores for both rich and poor countries, which is the average value of achievements in these three dimensions, are annually calculated and published as HDRs by UNDP. In fact three important objectives of UNDP are followed by publishing this well-known index:

- Breaking the dominance of the Gross National Product (GNP) as the index of development.

- Showing the distance of each country from the maximum possible value of the index.

- Comparing the countries in terms of both country rank and HDI values (Panigrahi \& Sivramkrishna, 2002).

Before 2010 the indicators used to measure HDI were as the following: life expectancy at birth for the health dimension, adult literacy rate and gross enrolment ratio for the education dimension, and Gross Domestic Product (GDP) per capita for the standard of living dimension. In HDI 20th anniversary edition in 2010, the indicators calculating the index were changed. 
HDI remained an aggregate measure of progress in three health, education and income dimensions, but in this edition the indicators used to measure progress in education and income dimensions were modified and the way they are aggregated was changed. In the education dimension, literacy indicator was replaced by mean years of schooling, and gross enrolment indicator was changed to expected years of schooling. The cause of these changes is that mean years of schooling is estimated more frequently and can discriminate better among countries. Expected years of schooling is consistent with the reframing of this dimension in terms of years.

In the standard of living dimension, gross domestic product (GDP) per capita was replaced by gross national income (GNI) per capita still at purchasing power parity (PPP) and logged. The cause of this change is that in a globalized world there could be large differences between the income of a country's residents and its domestic production. The possible reasons for this difference could be considered as sending residents' income abroad and receiving international remittances or aid flows.

Figure 1 shows the dimensions and indicators of the HDI index.

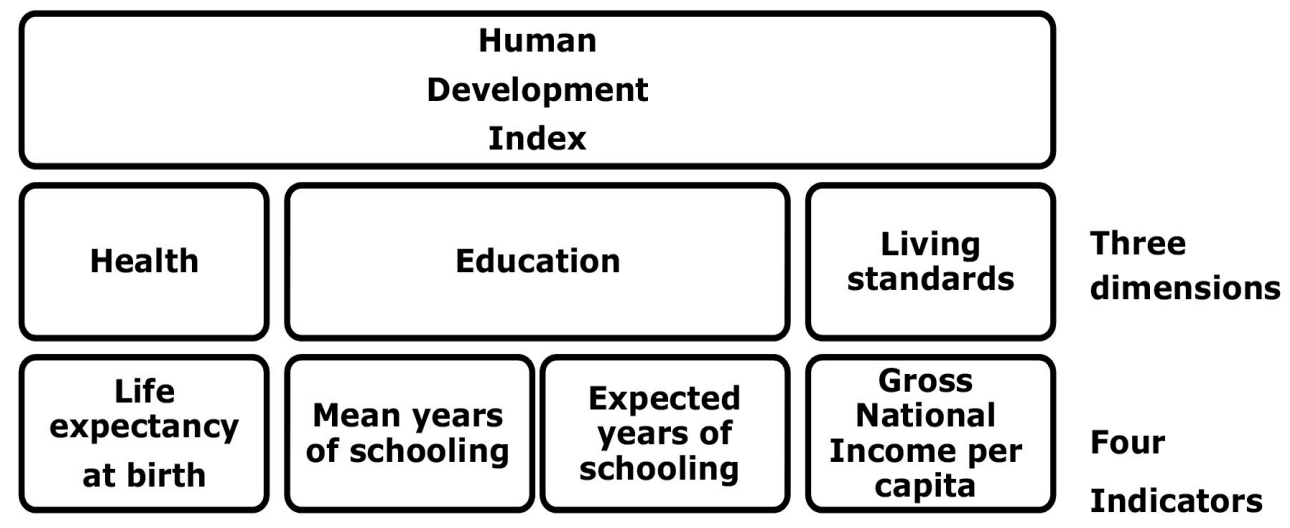

Figure 1. The HDI-three dimensions and four-indicators

In addition to modification of some indicators, a key change in the HDI 20th anniversary edition in 2010 was shifting to a geometric mean instead of arithmetic mean to aggregate the three dimension indicators. The reason of this change was implied as preventing the substitutability across dimensions (UNDP, 2010).

\subsection{The HDI methodology}

The HDI as a composite index of three different dimensions is measured for each country by UNDP. Then countries are ranked based on this index in terms of human development. For this purpose, the three core dimensions of the HDI are first put on a common $(0,1)$ scale. 
The rescaled indicator is:

$$
\text { Standardized value }=\frac{\text { actual value }- \text { minimum value }}{\text { range }(\text { maximum }- \text { minimum })}
$$

The maximum values are the highest values observed in the time series and the minimum values are set at 20 years for life expectancy indicator, 0 years for both education indicatorsand 100 dollars for gross national income (GNI) per capita indicator.

For education, equation (1) is applied to each of the two indicators, then a geometric mean of the resulting indices is created and finally, equation (1) is reapplied to the geometric mean of the indices using 0 as the minimum and the highest geometric mean of the resulting indices for the time period under consideration as the maximum. Since each indicator is a proxy for capabilities in the corresponding dimension, the transformation function from income to capabilities is likely to be concave. Thus the natural logarithm of the actual, minimum and maximum values is used for the income.

After that, the geometric mean of the dimensions is calculated to produce the Human Development Index (UNDP, 2011).

$$
H D I=\left(I_{\text {Life }}^{\frac{1}{3}} \cdot I_{\text {Education }}^{\frac{1}{3}} \cdot I_{\text {Income }}^{\frac{1}{3}}\right)
$$

Finally this index is used to rank countries in a descending order.

\subsection{Critiques of the HDI}

Among all of the indices which try to measure human development, the HDI has become one of the most widely used indicators for comparisons of welfare in its 20-year history because of its multidimensional well-being measurement as well as its transparency and simplicity (Harttgen \& Klasen, 2012). The HDI ranking has such a great impact on policy that some national governments announce their HDI ranking and their target ranking which they aspire to achieve (Engineer, King \& Roy, 2008). However, the HDI has received major criticisms since its inception, from HDR construction and composition to expand and include more dimensions (UNDP, 2010).

The first group of critiques such as Anand and Sen (1992) was concerned about dimensions and indicators of the HDI.

Ranis, Stewart and Samman (2005) emphasized neglecting some relevant dimensions and identified 11 categories that encompass allthe major dimensions of human development. They 
were mental well-being, empowerment, political freedom, social relations, community well-being, inequalities, work conditions, leisure conditions, political security, economic security and environmental conditions.

Sanusi (2008) tried to widen the scope of issues covered by the HDI and implied that housing facilities and housing conditions help in increasing the scope of human development. He examined housing facilities, housing adequacy, housing space and solid waste disposal as the issues that affect human development.

Bhanojirao (1991) suggested the inclusion of additional dimensions such as political, economic and social freedom, opportunities for being creative and productive, personal self-respect, and guaranteed human rights.

Neumayer (2001), Morse (2003), Moran, Wackernagel, Kitzes, Goldfinger and Boutaud (2008) and Dias, Mottos and Balestieri (2006) were concerned about consideration of natural resources conservation, environment and rational energy use concepts in development measuring. For example Neumayer (2001) and Morse (2003) believed in greening the HDI and proposed some methods to take into account the natural resource consumption and environmental dimensions in computing the development of countries.

Ogwang (1994) used a variable selection strategy and found that life expectancy would be the best choice to represent the three components of the HDI. Accordingly, a simplified HDI could be obtained, without loss of too much information and at a lower cost, by subtracting the life expectancy deprivation index from unity.

Engineer et al. (2008) argued that it is better to drop the income component from the HDI because it does not play its expected role of accessing a decent standard of living. They believed that income only double counts the effect of education and health components.

The second group of critiques believes that the HDI does not take into account inequality within countries. They believe that the HDI looks at the average achievements and does not take into account the distribution of human development within a country. The concept of inequality could be applied to variables such as gender, ethnic and income groups (Grimm, Harttgen, Klasen \& Misselhorn, 2008).

Sagar and Najam (1998) pointed out the use of the GDP per capita component as a proxy for average income does not allow for major differences in income distribution within a country.

Grimm et al. (2008) suggested a methodology to compute the three components and the overall HDI for quintiles of the income distribution. This technique allows comparisons of the levels in human development of the poor and non-poor within and across countries. 
Harttgen and Klasen (2012) proposed a method to calculate a proxy HDI at the household level. Their approach allows the analysis of the inequality in human development between population subgroups and by socioeconomic characteristics.

Hicks (1997) believed in inequality in the human development index and suggested to discount each dimensional index by one minus the Gini coefficient before the arithmetic mean over all three dimensions is taken. Therefore, index value for high inequality dimension and its contribution to the HDI is being lowered. He believed in publishing an Inequality-Adjusted Human Development Index (IAHDI) alongside the HDI.

The gender-related development index (GDI), was a UNDP attempt in the direction of this second group of criticisms. The GDI adjusts the HDI by gender inequalities in life expectancy, education and income dimensions. This index measures each indicator separately for men and women, and then calculates the harmonic mean of them (UNDP, 1995).

The third group of criticisms is related to HDI analytical framework and methodology.

McGillivray (1991) questioned both the composition of the HDI and its usefulness as an index of development and concluded that the HDI would flaw in its composition and more profoundly it could largely provide a little more information regarding inter-country development levels than the more traditional indicator GNP per capita.

Wolff, Chong and Auffhammer (2011) provided a detailed discussion of the three sources of data error: measurement error due to data updating, data noise due to formula revision and misclassification due to inconsistent thresholds of classifying a country's development status. They calculated the likelihood of each country's deviation from the original published HDI rank and emphasized that the statements based on ordinal HDI comparisons should be interpreted with great care.

Kelley (1991), Ravallion (1997) and Srinivasan (1994) criticized that the HDI uses an arbitrary equally weighting scheme of the three components.

Chowdhury and Squire (2006) considered applying a very simple weighting scheme to be universally wrong and implied that each of the HDI components should receive weights according to their contribution to human development.

Noorbakhsh (1998) suggested a number of modifications in two categories of technical issues ranging from those related to the components of the index to those relevant to the structure of the index. This resulted in a modified version of this index.

Desai (1991) proposed altering the weight for income above poverty level from zero to some small quantity as an improvement which needs to be pursued in future development of the index. 
Baliamoune-Lutz and McGillivray (2006) applied a framework to provide a fuzzy representation of the HDI and its three components. They found large differences in countries' ranks through fuzzy HDI methodology in comparison with non-fuzzy HDI.

Herrero, Martinez and Villar (2012) implied that the substantial modifications in the 2010 edition of the HDR-including changes in some of the variables, a different method of aggregation and the introduction of distributive considerations, still have some inconsistencies. They suggested a number of relative changes in some of the technical issues in the HDI methodology. Changes in the use of logs for the income variable and in the type of adopted normalization are some of the authors' suggested modifications.

Ravallion (2012) implied that using a multiplicative function (geometric mean) in calculating the HDI in the 2010 edition is a problematic form because the new multiplicative form of the HDI generates a large income gradient in the index's implicit valuations of two other life expectancy and schooling components of the HDI.

The effect of the last group of criticisms about the method of HDI computation on the ordinal rank of countries is obvious. Indeed, the different methodologies which are used to calculate the rank of countries in terms of constant criteria result in different ranking orders. The last group of criticisms which is related to HDI methodology used for ranking countries has been addressed in this study by proposing the Modified Similarity Multi Criteria Decision Making method as an effective MCDM technique.

\section{Multiple criteria decision making}

Many papers have proposed analytical models as aids in conflict management situations. Among the numerous approaches available for conflict management, one of the most prevalent is Multiple Criteria Decision Making. MCDM problem is a problem in which the decision maker intends to choose one out of several alternatives on the basis of a set of criteria. MCDM constitutes a set of techniques which can be used for comparing and evaluating the alternatives in terms of a number of qualitative and/or quantitative criteria with different measurement units for the purpose of selecting or ranking (Ozcan, Celebi \& Esnaf, 2011). It can help users understand the results of integrated assessments, including tradeoffs among policy objectives, and use these results in a systematic and defensible way to develop policy recommendations (Wang, Cheng \& Kun-Cheng, 2009). MCDM could be appropriate for evaluating a set of alternatives with respect to three objectives.

- Choosing the best alternative among a set of alternatives

- Sorting the alternatives into relatively homogeneous groups or arranging them in a preference order. 
- Ranking the alternatives in a descending or ascending order (Chen, Kilgour \& Hipel, 2011).

Great efforts in the field of developing and improving MCDM techniques are resulted in numerous approaches for effectively addressing general multiple criteria analysis decision problems (Deng, 2007). The application of these methods Depends on the structure of decision problems (Ozcan et al., 2011).

\subsection{TOPSIS technique}

Technique for Order Preference by Similarity to Ideal Solution (TOPSIS), one of the known classical MCDM methods, was first developed by Hwang and Yoon (1981) for solving an MCDM problem. Ranking of alternatives in the TOPSIS method is based on the shortest distance from the Positive Ideal Solution (PIS) and the farthest from the Negative Ideal Solution (NIS). This method simultaneously considers the distances of alternatives to both PIS and NIS, then the preference index for each alternative according to their relative closeness and a combination of these two distance measures is ranked (Hwang \& Yoon, 1981). Thus, TOPSIS minimizes the distance to the PIS while maximizing the distance to the NIS.

Kim, Park and Yoon (1997) and Shih, Shyur and Lee (2007) addressed four TOPSIS advantages: (1) a sound logic represents the rationale of human choice; (2) a scalar value which simultaneously considers both the best and worst alternatives; (3) a simple computation process that can be easily programmed and (4) ability of the performance measures of all alternatives on attributes to be visualized on a polyhedron, at least for any two dimensions.

Despite these advantages, the process of calculating the performance index for each alternative across all criteria in the TOPSIS approach may need more consideration (Chen \& Hwang, 1992). Under some circumstances when we compare two alternatives (vectors) just simply based on their distance from PIS and NIS, counter intuition outcomes may occur. Mathematically, comparing two alternatives in the form of two vectors is better represented by the magnitude of the alternatives and the degree of conflict between each alternative and the ideal solution, rather than just calculating the relative distance between them (Deng, 2007).

To avoid this concern about TOPSIS approach, Similarity approach presented by (Deng, 2007), makes use of the ideal solution concept in such a way that the most preferred alternative should have the highest degree of similarity to the PIS and the lowest degree of similarity to the NIS. The overall performance index of each alternative across all criteria is determined based on the combination of these two degrees of similarity measure concepts using alternative gradient and magnitude. 
In this paper we use a similarity based technique by (Deng, 2007) to rank countries in terms of HDI. In addition, during the presentation of Similarity multiple criteria analysis approach in the next section, a solution is provided for resolving a problem which exists in Deng's technique.

\subsection{Proposed modified Similarity technique methodology}

Similarity multiple criteria decision making approach can be presented in an algorithmic form as follows:

Step1. Determining the decision matrix:

$$
X=\left[\begin{array}{llll}
\mathrm{x}_{11} & \mathrm{x}_{12} & \ldots & \mathrm{x}_{1 \mathrm{~m}} \\
\mathrm{x}_{21} & \mathrm{x}_{22} & \ldots & \mathrm{x}_{2 \mathrm{~m}} \\
\ldots & \ldots & \mathrm{x}_{\mathrm{ij}} & \ldots \\
\mathrm{x}_{\mathrm{n} 1} & \mathrm{x}_{\mathrm{n} 2} & \ldots & \mathrm{x}_{\mathrm{nm}}
\end{array} \mid\right.
$$

A general multiple criteria analysis problem is represented as a decision matrix which consists of a set of alternatives $A_{i}(i=1,2, \ldots, n)$ to be evaluated against a set of criteria $C_{j}(j=1,2, \ldots, m)$.

In order to facilitate the development of the multiple criteria decision making approach, all of the criteria $C_{j}$ are assumed to be benefit criteria. It means that the larger the value of the performance of each alternative with respect to each criterion, the more preferable the alternative. If a criterion is a cost one, the transformation processes such as a reversing original criterion value, could be necessary to maintain the consistency of the decision matrix.

Step2. Determining the weighting vector as below:

$$
W=\left(w_{1}, w_{2}, \ldots, w_{j}, \ldots, w_{m}\right)
$$

In which the relative importance of criterion $C_{j}$ with respect to the overall objective of the problem is represented as $\mathrm{w}_{\mathrm{j}}$.

Step3. Normalizing the decision matrix through Euclidean normalization:

$$
x_{i j}^{\prime}=\frac{x_{i j}}{\left(\sum_{k=1}^{n} x_{i k}^{2}\right)^{1 / 2}}
$$


As a result, a normalized decision matrix can be determined as:

$$
X^{\prime}=\left|\begin{array}{cccc}
x_{11}^{\prime} & x_{12}^{\prime} & \cdots & x_{1 m}^{\prime} \\
x_{21}^{\prime} & x_{22}^{\prime} & \cdots & x_{2 m}^{\prime} \\
\cdots & \cdots & x_{i j}^{\prime} & \cdots \\
x_{n 1}^{\prime} & x_{n 2}^{\prime} & \cdots & x_{n m}^{\prime}
\end{array}\right|
$$

Step4. Calculating the performance matrix:

The weighted performance matrix which reflects the performance of each alternative with respect to each criterion is determined by multiplying the normalized decision matrix (6) by the weight vector (4).

$$
Y=\left(\begin{array}{cccc}
w_{1} x_{11}^{\prime} & w_{2} x_{12}^{\prime} & \ldots & w_{m} x_{1 m}^{\prime} \\
w_{1} x_{21}^{\prime} & w_{2} x_{22}^{\prime} & \ldots & w_{m} x_{2 m}^{\prime} \\
\cdots & \cdots & w_{i} x_{i j}^{\prime} & \cdots \\
w_{1} x_{n 1}^{\prime} & w_{2} x_{n 2}^{\prime} & \ldots & w_{m} x_{n m}^{\prime}
\end{array}\right]=\left[\begin{array}{cccc}
y_{11} & y_{12} & \cdots & y_{1 m} \\
y_{21} & y_{22} & \cdots & y_{2 m} \\
\ldots & \ldots & y_{i j} & \cdots \\
y_{n 1} & y_{n 2} & \cdots & y_{n m}
\end{array}\right]
$$

Step5. Determining the PIS and the NIS:

The positive (negative) ideal solution consists of the best (worst) criteria values attainable from all the alternatives. Deng (2007) enumerated the advantages of using these two concepts as: their simplicity and comprehensibility, their computational efficiency, and their ability to measure the relative performance of the alternatives in a simple mathematical form.

$$
\begin{array}{r}
I_{j}^{+}=\max y_{i j} \\
i=1,2, \ldots, n \\
I_{j}^{-}=\operatorname{miny} y_{i j} \\
i=1,2, \ldots, n
\end{array}
$$

Step6. Calculating the conflict index between the alternatives and the PIS and the NIS:

As we implied earlier according to Deng (2007) the logic of TOPSIS method in ranking the alternatives based on their distances from the positive and the negative ideal solutions could be problematic in some circumstances. In this regard some researchers introduce better measures than just distance, in order to compare the alternatives to PIS and NIS (see, e.g., Zhongliang, 2011). Deng (2007) introduced the concept of alternative gradient to represent the conflict of alternatives in multiple criteria analysis problems.

Assume that $A_{i}$ is a vector which represents an alternative and $\mathrm{I}_{j}{ }^{+}$and $\mathrm{I}_{j}^{-}$are two vectors of positive and negative ideal solution in a given multiple criteria analysis problem. These vectors can be considered in the m-dimensional real space. The angle between $A_{i}$ and $I_{j}^{+}\left(I_{j}^{-}\right)$in the m-dimensional real space, which is shown by $\theta_{i}^{+}\left(\theta_{i}^{-}\right)$, is a good measure of conflict between the vectors. The above vectors and the degree of conflict between them are shown in Figure 2 . 
The situation of conflict occurs when $\theta_{i} \neq 0$, that is, when the gradients of $A i$ and $\mathrm{I}_{j}^{+}\left(\mathrm{I}_{j}^{-}\right)$are not coincident. Thus the conflict index is equal to one as the corresponding gradient vectors lie in the same direction, and the conflict index is zero when $\theta_{i}=\pi / 2$ which indicates that their gradient vectors have the perpendicular relationship with each other.

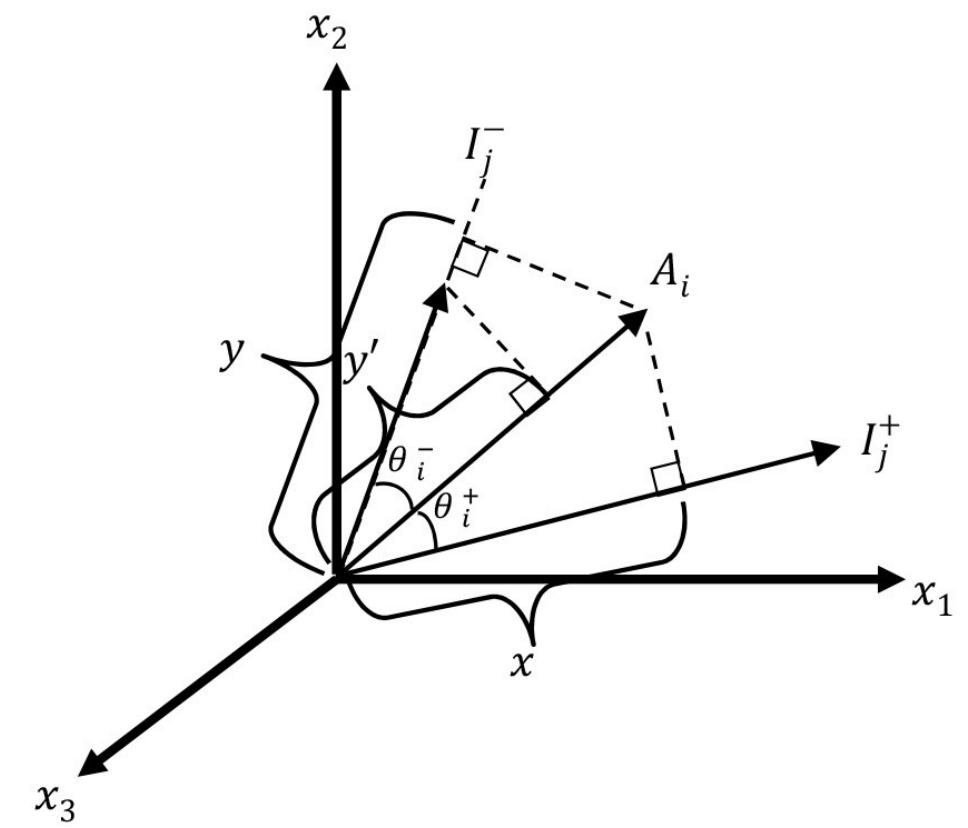

Figure 2. The degree of conflict between alternatives and $\mathrm{I}_{j}^{+}\left(\mathrm{I}_{\mathrm{j}}^{-}\right)$

The degree of conflict between alternative $(\mathrm{Ai})$ and $\mathrm{I}_{j}{ }^{+}\left(\mathrm{I}_{\mathrm{j}}{ }^{-}\right)$is determined by:

$$
\begin{aligned}
\cos \theta_{i}^{+} & =\frac{\sum_{j=1}^{m} y_{i j} * I_{j}^{+}}{\left(\sum_{j=1}^{m} y_{i j}^{2} \sum_{j=1}^{m}\left(I_{j}^{+}\right)^{2}\right)^{1 / 2}} \\
i & =1,2, \ldots, n \\
\cos \theta_{i}^{-} & =\frac{\sum_{j=1}^{m} y_{i j} * I_{j}^{-}}{\left(\sum_{j=1}^{m} y_{i j}^{2} \sum_{j=1}^{m}\left(I_{j}^{-}\right)^{2}\right)^{1 / 2}} \\
i & =1,2, \ldots, n
\end{aligned}
$$

Step7. Calculating the degree of similarity of the alternatives between each alternative and the PIS and the NIS:

Based on the degree of the conflict between the alternatives and the PIS and the NIS, the degree of similarity between the alternatives and $\mathrm{I}_{j}{ }^{+}\left(\mathrm{I}_{j}^{-}\right)$can be calculated. The degree of similarity denoted as $\mathrm{S}_{i}{ }^{+}$, measures the relative similarity of the alternative $\mathrm{A}_{i}$ to $\mathrm{I}_{j}{ }^{+}$, and the degree of similarity denoted as $S_{i}^{-}$measures the relative similarity of the alternative $A_{i}$ to $I_{j}^{-}$. 


$$
S_{i}^{+}=\frac{x}{\left|I_{j}^{+}\right|}=\frac{\cos \theta_{i}^{+}\left|A_{i}\right|}{\left|I_{j}^{+}\right|}
$$

The problem caused by $S_{i}^{-}$in Deng's method is that if we calculate the $S_{i}^{-}$just like $S_{i}^{+}$, that is if we consider the equation $S_{i}^{-}=\frac{y}{\left|I^{-}\right|}$, we will not have a number between 0 and 1 for $S_{i}^{-}$and we will have problem with calculating the performance index in the next step.

As it is shown in Figure 2, $\mathrm{x}$ is the projection of the alternative vector $\mathrm{A}_{i}$ on the PIS vector $\mathrm{I}_{j}^{+}$. Since the PIS has the greatest value among alternatives, the $A_{i}$ vector is equal or shorter than it. As a result we will have a number between 0 and 1 for $S_{i}{ }^{+}$. Similarly $y$ is the projection of the alternative vector $A_{i}$ on the NIS vector $I_{j}{ }^{-}$. But in this case as the NIS has the lowest value among alternatives, $\mathrm{y}$ is equal or longer than $\mathrm{I}_{j}^{-}$and the problem is caused in Deng's method. In order to fix the problem we need another vector, and $y^{\prime}$ is the best choice. As it is shown in Figure $2, y^{\prime}$ is the projection of the NIS vector $I_{j}^{-}$on the alternative vector $w A_{i}$ hich is always lower than the alternative vector. Thus we propose the below equation to overcome the problem related to Deng's method.

$$
S_{i}^{-}=\frac{y^{\prime}}{\left|A_{i}\right|}=\frac{\cos \theta_{i}^{-}\left|I_{j}^{-}\right|}{\left|A_{i}\right|}
$$

With this change in calculation we will have a number between 0 and 1 for $S_{i}^{-}$just as $S_{i}^{+}$.

Step8. Calculating the overall performance index for each alternative across all criteria:

This index can be calculated based on the concept of the degree of similarity of alternative $A_{i}$ relative to the ideal solutions.

$$
\begin{gathered}
P_{i}=\frac{S_{i}^{+}}{S_{i}^{+}+S_{i}^{-}} \\
i=1,2, \ldots, n
\end{gathered}
$$

In contrast to the Similarity technique which is presented by Deng (2007), in the modified Similarity technique $S_{i}^{-}$and $P_{i}$ are always between zero and one. To the extent $A_{i}$ become more similar to $S_{i}^{+}$and less similar to $S_{i}^{-}$, the overall performance index $P_{i}$ become near to 1 .

Step9. Ranking the alternatives in the descending order of the performance index value. 


\section{Ranking countries in termsof HDI through modified Similarity technique}

In this part we apply the Modified Similarity technique to rank countries in terms of HDI. For this purpose we use the four HD indices (life expectancy at birth, mean years of schooling, expected years of schooling and GNI per capita) mentioned in the 2010 and 2011 HDRs to rank 187 countries which have been investigated in the 2011 HDR. Since there are quite a large number of countries in 2011 HDR, we follow the steps for one country (France) as a sample. Data related to four human development indices for this country is shown in Table 1.

\begin{tabular}{|c|c|c|c|c|}
\hline Country & Life expectancy at birth & Mean years of schooling & Expected years of schooling & log GNI \\
\hline France & 81.5 & 10.6 & 16.1 & 10.32 \\
\hline
\end{tabular}

Table 1. Data related to four human development indicators for France

Before ranking the countries we use equation (1) which already was expressed in the second part of the article (The HDI methodology) to put data on a common $(0,1)$ scale. The result is shown in Table 2. After this rescaling, we have our required data to follow the steps of Modified Similarity technique as below:

Step1. Determining the decision matrix

In this matrix 187 countries which have been investigated in the $2011 \mathrm{HDR}$, are considered to be alternatives and the four HD indices formed the criteria. Data which are rescaled through equation (1) constitute our decision matrix elements.

The sample decision matrix for France is as shown Table 2.

\begin{tabular}{|l|c|c|c|c|}
\hline Country & Life expectancy at birth & Mean years of schooling & Expected years of schooling & log GNI \\
\hline France & 0.970032 & 0.809160 & 0.894444 & 0.819100
\end{tabular}

Table 2. Sample Decision Matrix

Step2. Determining the weighting vector

Since the HDR has not determined the relative weights of the four indices, we pass up this step. Although calculating the weights are feasible through weighting techniques like Shannon's Entropy and AHP. 
Step3. Normalizing the decision matrix

In this step we normalize the decision matrix through Euclidean normalization based on equation (5). The sample normalized decision matrix for France is as Table 3.

\begin{tabular}{|c|c|c|c|c|}
\hline Country & Life expectancy at birth & Mean years of schooling & Expected years of schooling & $\log$ GNI \\
\hline France & 0.088967 & 0.094808 & 0.092772 & 0.096348 \\
\hline
\end{tabular}

Table 3. Sample Normalized Decision Matrix

Step4. Calculating the performance matrix

This step is passed up following step 2.

Step5. Determining the PIS and the NIS

The PIS and the NIS are attainable from all the alternatives (184 countries) across all four criteria according to equation (8).The PIS and the NIS are shown in Table 4.

\begin{tabular}{|c|c|c|c|c|}
\hline Ideal Solutions & Life expectancy at birth & Mean years of schooling & Expected years of schooling & log GNI \\
\hline $\mathrm{I}^{+}$ & 0.091716 & 0.112696 & 0.103720 & 0.117627 \\
\hline $\mathrm{I}^{-}$ & 0.040216 & 0.010733 & 0.025354 & 0.016418 \\
\hline
\end{tabular}

Table 4. PIS and NIS

Step6. Calculating the conflict index

The degree of conflict between alternatives and PIS and NIS is calculated based on equation (9) and is shown in Table 6.

\begin{tabular}{|c|c|}
\hline $\cos \theta^{+}$ & 0.998031 \\
\hline $\cos \theta^{-}$ & 0.889139 \\
\hline
\end{tabular}

Table 5.Degree of conflict between the alternative (France as a sample) and PIS and NIS

Step7. Calculating the degree of similarity

The degree of similarity of the alternatives between each alternative and the PIS and the NIS is calculated based on equations (10) and (11). The degree of similarity of France as a sample and $\mathrm{I}+(\mathrm{I}-)$ is shown in Table 6. 


\begin{tabular}{|c|c|}
\hline $\mathbf{s}^{+}$ & 0.870772 \\
\hline $\mathbf{s}^{-}$ & 0.245147 \\
\hline
\end{tabular}

Table 6. Degree of similarity of alternatives (France as a sample) and PIS and NIS

Step8. Calculating the overall performance index

The overall performance index for each alternative across all four criteria is calculated based on equation (12). This index is shown for France as a sample in Table 7.

\section{$P_{i}$}

$$
0.870772
$$

Table 7. The overall performance index for alternatives (France as a sample) across all criteria

Step9. Ranking the alternatives

Finally the alternatives could be ranked in the descending order of the $\mathrm{P}_{\mathrm{i}}$ index value.

The first ten countries which are ranked through Modified Similarity technique are reported in Table 8. The HDI ranking of 2011 HDR is also shown in Table 8.

\begin{tabular}{|c|c|c|}
\hline Countries & $\begin{array}{c}\text { Ranking through } \\
\text { Modified Similarity technique }\end{array}$ & 2011 HDR ranking \\
\hline Norway & 1 & 1 \\
\hline Australia & 2 & 2 \\
\hline New Zealand & 3 & 5 \\
\hline United States & 4 & 4 \\
\hline Ireland & 5 & 7 \\
\hline Germany & 6 & 9 \\
\hline Canada & 7 & 6 \\
\hline Netherlands & 8 & 3 \\
\hline Denmark & 9 & 16 \\
\hline Sweden & 10 & 10 \\
\hline
\end{tabular}

Table 8. First ten counties ranked through Modified Similarity technique and their related 2011 HDR rank 


\section{Conclusions}

One of the major criticisms of the HDI is related to the method of HDI calculation. Until 2010 HDI was being computed by the average of the four HDI indicators. Then countries were ranked according to this overall index. In the 2010 and 2011 HDRs, UNDP changed its method of computing the HDI from simple average to geometric average. But this new method is still being faced criticisms. On the other hand there are lots of efficient multiple criteria decision making methods which are suitable for the purpose of ranking alternatives across a set of criteria. These methods could overcome criticisms that are related to HDI computation methodology. So the first contribution of this study was applying one of the best MCDM approaches which is Similarity technique introduced by (Deng, 2007) in order to construct a better logic for ranking countries based on HDI. Similarity technique not only has the advantages of TOPSIS method but also eliminates its major weaknesses. Like TOPSIS, the Similarity method compares the alternatives with the positive and the negative ideal solutions but the comparison in Similarity technique is based on a broader concept. In this method the overall performance index of each alternative across all criteria is determined based on the combination of the degree of similarity to PIS and NIS using alternative gradient and magnitude.

Another contribution of the study was proposing the Modified Similarity technique, which could eliminate the problem caused by the method of calculating the similarity of the alternative to NIS $\left(S_{i}^{-}\right)$in Deng's method. This effective modified analytical tool could be applied for all ranking purposes. Thus Future studies could apply the proposed method to other areas of decision making or ranking other alternatives.

The results of ranking countries by the Modified Similarity technique shown in Table 8 are somewhat different from the 2011 HDR ranking. The reason of this difference is that the logic of comparing alternatives in MCDM methods is different from the simple or geometric average which is used by UNDP for ranking countries in terms of HDI. Since MCDM methods are known as formal approaches applied in a wide area of selecting or ranking alternatives in terms of various criteria, they can be useful for the purpose of proper ranking of the countries in annual human development reports.

As we pointed out earlier, another criticisms of the UNDP method for ranking countries based on HDI, is applying the equally weighting scheme of the HDI components. however we did not addressing this issue in the article, it is recommended that calculating the four HDR indices' weights through weighting techniques like Shannon's Entropy and AHP would be considered in future studies. The logic of weighting criteria through these techniques is different. Shannon's Entropy is a kind of objective weighting methods of qualitative analysis combined with quantities analysis which can measure the useful information of obtained data. The smaller the information entropy is, the bigger the weight of the indicator is (Dong \& Gao, 2012). In AHP 
method pair-wise comparison between criteria are made by the experts or decision makers to signify the comparative weights of these criteria (Bozbura, Beskese \& Kahraman, 2007).

There are numerous MCDM methods which can be used for comparing and evaluating the alternatives in terms of a number of criteria for the purpose of selecting or ranking. Some of the most frequently used MCDM techniques are AHP, TOPSIS, ELECTRE, Superiority and Inferiority Ranking (SIR) and Preference Ranking Organization Method for Enrichment Evaluations (PROMETHEE). These Decision making methodologies are separated from each other through different calculation methods. For example the core process in AHP is to create hierarchy and pair-wise comparison matrices in all the levels of hierarchy. In TOPSIS method, the calculation of each alternative distance from the positive ideal and the negative ideal solutions draws attention and in ELECTRE, determination of concordance and discordance metrics for each criterion is important (Ozcan et al., 2011). Applying these different MCDM methodologies could results in different ranking orders according to their main processes. So as a recommendation, comparing the results of other MCDM techniques with both Modified Similarity technique and the HDR ranking results could be useful for the purpose of selecting the best technique for ranking the countries in terms of HDI.

\section{References}

Anand, S., \& Sen, A. (1992). Human Development Index: Methodology and Measurement. Human Development Report Office Occasional Paper 12. UNDP, New York.

http://hdr.undp.org/en/reports/global/hdr1994/papers/

Baliamoune-Lutz, M., \& McGillivray, M. (2006). Fuzzy Well-being Achievement in Pacific Asia. Journal of the Asia Pacific Economy, 11(2), 168-177. http://dx.doi.org/10.1080/13547860600591101

Bhanojirao, V.V. (1991). Human development report 1990: review and assessment. World Development, 19(10), 1451-1460. http://dx.doi.org/10.1016/0305-750X(91)90087-X

Bozbura, F.T., Beskese, A., \& Kahraman, C. (2007). Prioritization of human capital measurement indicators using fuzzy AHP. Expert Systems with Applications, 32, 1100-1112. http://dx.doi.org/10.1016/j.eswa.2006.02.006

Chen, S., \& Hwang, C. (1992). Fuzzy Multiple Attribute Decision Making: Methods and applications. New York: Springer-Verlag.

Chen, Y., Kilgour, D., \& Hipel, K. (2011). An extreme-distance approach to multiple criteria ranking. Mathematical and Computer Modelling, 53, 646-658. 
Chowdhury, S., \& Squire, L. (2006). Setting Weights for Aggregate Indices: An Application to the Commitment to Development Index and Human Development Index. Journal of Development Studies, 42(5), 761-771. http://dx.doi.org/10.1080/00220380600741904

Deng, H. (2007). A Similarity-Based Approach to Ranking Multicriteria Alternatives. In D.-S. Huang, L. Heutte and M. Loog (Eds.). Advanced intelligent computing theories and applications with Aspects of Artificial Intelligence (pp. 253-262). Berlin Heidelberg: Springer-Verlag. http://dx.doi.org/10.1007/978-3-540-74205-0_28

Desai, M. (1991). Human development: concepts and measurement. European Economic Review, 35, 350-357. http://dx.doi.org/10.1016/0014-2921(91)90136-7

Dias, A., Mattos, R., \& Balestieri, A. (2006). The limits of human development and the use of energy and natural resource. Energy Policy, 34, 1026-1031.

http://dx.doi.org/10.1016/j.enpol.2004.09.008

Dong, Q., \& Gao, C. (2012). Knowledge Engineering, Intellectual Capital of Creative Industry Park Based on Multi-objective Decision-Making and Entropy Methods. Systems Engineering Procedia, 3, 326-332. http://dx.doi.org/10.1016/j.sepro.2011.11.037

Engineer, M., King, I., \& Roy, N. (2008). The human development index as a criterion for optimal planning. Indian Growth and Development Review, 1(2), 172-192.

http://dx.doi.org/10.1108/17538250810903774

Grimm, M., Harttgen, K., Klasen, S., \& Misselhorn, M. (2008). A Human Development Index by Income Groups. World Development, 36(12), 2527-2546.

http://dx.doi.org/10.1016/j.worlddev.2007.12.001

Harttgen, K., \& Klasen, S. (2012). A Household-Based Human Development Index. World Development, 40(5), 878-899. http://dx.doi.org/10.1016/j.worlddev.2011.09.011

Herrero, C., Martinez, R., \& Villar, A. (2012). A Newer Human Development Index. Journal of Human Development and Capabilities, 13(2), 247-268.

http://dx.doi.org/10.1080/19452829.2011.645027

Hicks, D. (1997). The inequality-adjusted human development index: Constructive proposal. World Development, 28(8), 1283-1298. http://dx.doi.org/10.1016/S0305-750X(97)00034-X

Hwang, C., \& Yoon, K. (1981). Multiple Attribute Decision Making: Theory and Applications. New York: Springer-Verlag.

Kelley, A. (1991). The human development index: Handle with care. Population and Development Review, 17(2), 315-324. http://www.jstor.org/stable/1973733 
Kim, G., Park, C., \& Yoon, K. (1997). Identifying investment opportunities for advanced manufacturing systems with comparative-integrated. International Journal of Production Economics, 50, 23-33. http://dx.doi.org/10.1016/S0925-5273(97)00014-5

McGillivray, M. (1991). The human development index: yet another redundant composite development indicator? World Development, 19(10), 1461-1468. http://dx.doi.org/10.1016/0305750X(91)90088-Y

Moran, D., Wackernagel, M., Kitzes, J., Goldfinger, S., \& Boutaud, A. (2008). Measuring sustainable development - Nation by nation. Ecological Economics, 64, 470-479. http://dx.doi.org/10.1016/j.ecolecon.2007.08.017

Morse, S. (2003). Greening the United Nations' Human Development Index. Sustainable Development, 11, 183-198. http://dx.doi.org/10.1002/sd.219

Neumayer, E. (2001). The human development and sustainability - a constructive proposal. Ecological Economics, 39, 101-114. http://dx.doi.org/10.1016/S0921-8009(01)00201-4

Noorbakhsh, F. (1998). A Modified human development index. World Development, 26 (3), 517-528. http://dx.doi.org/10.1016/S0305-750x(97)10063-8

Ogwang, T. (1994). The choice of principal variables for computing the human development index. World Development, 22(12), 2011-2024. http://dx.doi.org/10.1016/0305-750x(94)90189-9

Ozcan, T., Celebi, N., \& Esnaf, S. (2011). Comparative analysis of multi-criteria decision making methodologies and implementation of a warehouse location selection problem. Expert Systems with Applications, 38, 9773-9779. http://dx.doi.org/10.1016/j.eswa.2011.02.022

Panigrahi, R., \& Sivramkrishna, S. (2002). An Adjusted Human Development Index: Robust Country Rankings with Respect to the Choice of Fixed Maximum and Minimum Indicator Values. Journal of Human Development, 3(2), 301-311.

http://dx.doi.org/10.1080/14649880220147365

Porter, J., \& Purser, C. (2008). Measuring relative sub-national human development: An application of the United Nation's Human Development Index using geographic information systems. Journal of Economic and Social Measurement, 33, 253-269.

http://iospress.metapress.com/content/90h320124103u6p2/

Ranis, G., Stewart, F., \& Samman, E. (2005). Human development: Beyond the HDI. Economic Growth Center, Yale University. http://www.econ.yale.edu/growth_pdf/cdp916.pdf

Ravallion, M. (1997). Good and bad growth: The human development reports. World Development, 25(5), 631-638. http://dx.doi.org/10.1016/S0305-750X(96)00141-6 
Ravallion, M. (2012). Troubling tradeoffs in the Human Development Index. Journal of Development Economics, 99 (2), 201-209. http://dx.doi.org/10.1016/j.jdeveco.2012.01.003

Sagar, A., \& Najam, A. (1998). The human development index: a critical review. Ecological Economics, 25, 249-264. http://dx.doi.org/10.1016/S0921-8009(97)00168-7

Sanusi, Y.A. (2008). Application of human development index to measurement of deprivations among urban households in Minna, Nigeria. Habitat International, 32, 384-398. http://dx.doi.org/10.1016/j.habitatint.2007.11.009

Shih, H., Shyur, H., \& Lee, E. (2007). An extension of TOPSIS for group decision making. Mathematical and Computer Modelling, 45, 801-813. http://dx.doi.org/10.1016/j.mcm.2006.03.023

Srinivasan, T. (1994). Human development: A new paradigm or reinvention of the wheel? American Economic Review, 84(2), 238-243. http://www.jstor.org/stable/2117836

UNDP. (1990). Human Development Report 1990. UNDP, New York.

http://hdr.undp.org/en/reports/global

UNDP. (1995). Human Development Report 1995. Gender and human development. UNDP, New York. http://hdr.undp.org/en/reports/global

UNDP. (2003). Human Development Report 2003. Millennium Development Goals: A compact among nations to end human poverty. UNDP, New York.

http://hdr.undp.org/en/reports/global

UNDP. (2010). Human Development Report 2010. The Real Wealth of Nations: Pathways to Human Development. UNDP, New York. http://hdr.undp.org/en/reports/global

UNDP. (2011). Human Development Report 2011. Sustainability and Equity: A Better Future for All. UNDP, New York. http://hdr.undp.org/en/reports/global

Wang, J., Cheng, C., \& Kun-Cheng, H. (2009). Fuzzy hierarchical TOPSIS for supplier selection. Applied Soft Computing, 9, 377-386. http://dx.doi.org/10.1016/j.asoc.2008.04.014

Wolff, H., Chong, H., \& Auffhammer, M. (2011). Classification, detection and consequences of data error: evidence from the Human Development Index. The Economic Journal, 121, 843-870. http://www.nber.org/papers/w16572

Yassin, S.M., Shaffril, H.A., Hassan, M.S., Othman, M.S., Samah, B.A., Samah, A.A., et al. (2011). Human Development Index of the Rural Community in the Three Major Cities along Pahang River and Muar River, Malaysia. Australian Journal of Basic and Applied Sciences, 5(8), 876-884. http://www.ajbasweb.com/ajbas/2011/August-2011/876-884.pdf 
Zhongliang, Y. (2012). Approach to group decision making based on determining the weights of experts by using projection method. Applied Mathematical Modelling, 36(7), 2900-2910. http://dx.doi.org/10.1016/j.apm.2011.09.068

Journal of Industrial Engineering and Management, 2014 (www.jiem.org)

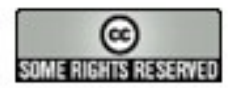

Article's contents are provided on a Attribution-Non Commercial 3.0 Creative commons license. Readers are allowed to copy, distribute and communicate article's contents, provided the author's and Journal of Industrial Engineering and Management's names are included. It must not be used for commercial purposes. To see the complete license contents, please visit http://creativecommons.org/licenses/by-nc/3.0/. 